Baum, S.D., Denkenberger, D.C., A Pearce, J.M., Robock, A., Winkler, R. Resilience to global food supply catastrophes. Environment, Systems and Decisions 35(2), pp 301-313 (2015). DOI: 10.1007/s10669-015-9549-2

\title{
Resilience to Global Food Supply Catastrophes
}

\author{
Seth D. Baum, ${ }^{1}$ David C. Denkenberger, ${ }^{1}$ Joshua M. Pearce, ${ }^{2,3}$ Alan Robock, ${ }^{4}$ and Richelle \\ Winkler ${ }^{5}$ \\ 1. Global Catastrophic Risk Institute \\ 2. Department of Materials Science \& Engineering, Michigan Technological University \\ 3. Department of Electrical \& Computer Engineering, Michigan Technological University \\ 4. Department of Environmental Sciences, Rutgers University \\ 5. Department of Social Sciences, Michigan Technological University
}

\begin{abstract}
Many global catastrophic risks threaten major disruption to global food supplies, including nuclear wars, volcanic eruptions, asteroid and comet impacts, and plant disease outbreaks. This paper discusses options for increasing the resilience of food supplies to these risks. In contrast with local catastrophes, global food supply catastrophes cannot be addressed via food aid from external locations. Three options for food supply resilience are identified: food stockpiles, agriculture, and foods produced from alternative (non-sunlight) energy sources including biomass and fossil fuels. Each of these three options has certain advantages and disadvantages. Stockpiles are versatile but expensive. Agriculture is efficient but less viable in certain catastrophe scenarios. Alternative foods are inexpensive pre-catastrophe but need to be scaled up post-catastrophe and may face issues of social acceptability. The optimal portfolio of food options will typically include some of each, and will additionally vary by location as regions vary in population and access to food input resources. Furthermore, if the catastrophe shuts down transportation, then resilience requires local self-sufficiency in food. Food supply resilience requires not just the food itself, but also the accompanying systems of food production and distribution. Overall, increasing food supply resilience can play an important role in global catastrophic risk reduction. However, it is unwise to attempt maximizing food supply resilience, because doing so comes at the expense of other important objectives, including catastrophe prevention. Taking all these issues into account, the paper proposes a research agenda for analysis of specific food supply resilience decisions.
\end{abstract}

Keywords: global catastrophic risk; food security; resilience; alternative foods; nuclear winter; volcanic winter

\section{Introduction}

Human civilization is threatened by a range of global catastrophic risks. The severity of such catastrophes is so large (indeed, it may be infinite) that these risks are important even if their probability is low. And so, scholars over several decades have argued that reducing these risks should be an important priority for society today (e.g., Sagan 1983; Ng 1991; Bostrom 2002; Beckstead 2013). ${ }^{1}$

Several known global catastrophic risks cause harm to human civilization by disrupting global food supplies, threatening severe global food security crises. Volcanic eruptions, asteroid

\footnotetext{
${ }^{1}$ The literature on these risks sometimes uses other terminology besides "global catastrophic risks", such as existential risks, extinction risks, or simply catastrophic risks. The distinction between these terms is not crucial for this paper. What matters is that these are all major risks to the viability of human civilization.
} 
Baum, S.D., Denkenberger, D.C., A Pearce, J.M., Robock, A., Winkler, R. Resilience to global food supply catastrophes. Environment, Systems and Decisions 35(2), pp 301-313 (2015). DOI: 10.1007/s10669-015-9549-2

and comet impacts, and nuclear wars all send particulate matter into the stratosphere. The particles spread globally, blocking incoming sunlight, rapidly lowering surface temperatures and reducing precipitation, and in turn lowering agricultural yields (Robock et al. 2009; Xia et al. 2015). A rapid increase in surface temperatures can follow from the abrupt cessation of stratospheric geoengineering, a technology proposed in response to global warming (e.g., Matthews and Caldeira 2007); ${ }^{2}$ this rapid warming could have similarly harmful agricultural effects. Even without geoengineering, natural climate change could also be abrupt (Lenton et al. 2008; Valdes 2011). Plant pathogens and invasive species, including novel organisms produced through biotechnology, could destroy major classes of crops (Dudley 2002; Mann 1999; Saigo 2000). There may be additional risks to global food supplies that have not yet been identified. These unknown risks could relate to environmental change, emerging technologies, and/or some other force. ${ }^{3}$ Because so many known global catastrophic risks impair food supplies, it is likely that unknown global catastrophic risks would as well. Collectively, these risks make risks to food supplies one of the largest classes of global catastrophic risk.

Ideally, these catastrophes would be prevented, such that there would be no major loss of food. To the extent that these catastrophes can be prevented, efforts to prevent them should be made. However, such efforts may not succeed. Furthermore, some of the risks, such as volcanic eruptions, cannot readily be prevented. Finally, the unknown risks, if there are any, potentially could be prevented, but it is not known how to do so. For these reasons, it is possible that a global food supply catastrophe will occur, despite efforts made to prevent it.

The prospect of global food supply catastrophe suggests a role for increasing civilization's resilience to such catastrophes. Resilience can be defined as "the ability to prepare and plan for, absorb, recover from, and more successfully adapt to adverse events” (NAS 2012:1). Risk analysts have increasingly recognized the importance of resilience in managing a variety of risks (Haimes 2009; Aven 2011; Park et al. 2013; Linkov et al. 2014), including global catastrophic risks (Maher and Baum 2013; Baum and Handoh 2014). A resilient system is able to retain critical functionality in the face of disruptions, even while it may make adaptations of noncritical attributes. In the face of global food supply catastrophes, a resilient global human system will adapt its food procurement practices to keep people alive and keep civilization intact.

In this paper, we discuss prospects for increasing resilience to global food supply catastrophes. The paper synthesizes prior literature to derive some general insights about how resilience to global food supply catastrophes could and should be achieved. The paper additionally proposes a research agenda for analyzing specific resilience decisions.

For local food supply catastrophes, the loss of food in one location can be addressed by importing food from other locations. Indeed, food aid is commonly donated from distant locations during times of local catastrophe or famine. However, when the catastrophe is global, all locations are affected, so there may be no location with surplus food to donate. Furthermore, transportation systems may be nonoperational, in which case any surplus foods could not be

\footnotetext{
${ }^{2}$ Stratospheric geoengineering is a procedure in which aerosols, typically sulfates, are injected into the stratosphere in order to block incoming sunlight, thereby cooling the surface. The effect is similar to the cooling from volcano eruptions, asteroid or comet impacts, or nuclear wars, except that with geoengineering the aerosol injection is controlled to optimize the cooling. However, if aerosol injection ceases for whatever reason, then temperatures rapidly rise to where they would have been without any geoengineering.

${ }^{3}$ Such risks are not completely unknown. For example, we know that they threaten global catastrophe. But such risks are relatively unknown compared to the risks named here.
} 
Baum, S.D., Denkenberger, D.C., A Pearce, J.M., Robock, A., Winkler, R. Resilience to global food supply catastrophes. Environment, Systems and Decisions 35(2), pp 301-313 (2015). DOI: 10.1007/s10669-015-9549-2

delivered. Therefore, resilience could require local self-sufficiency in food, and potentially in other resources as well.

Traditionally, calls for increasing resilience to global food supply catastrophes have focused on stockpiling food before the catastrophe so that it is available for consumption after (Schneider 1976; Maher and Baum 2013). This is indeed a viable option. However, it is also very expensive, and worsens pre-catastrophe food security, which is currently a substantial problem. Because of this, we also consider two other options. The second option is to continue agriculture postcatastrophe, albeit in diminished form. Depending on the specifics of the catastrophe scenario, some agriculture may be possible. The third option is to produce food from alternative energy sources, in particular biomass and fossil fuels. ${ }^{4}$ Such "alternative foods" could play an important role during catastrophes in which sunlight is blocked or in which traditional sunlight-based agriculture is not adequate (Denkenberger and Pearce 2014; 2015).

The paper is organized as follows. Section 2 defines global food security catastrophes in terms of the resilience of human systems. Section 3 surveys the three food security options: food stockpiles, agriculture, and alternative foods. Section 4 discusses geographic issues important to increasing local resilience to global food security catastrophes. Section 5 discusses implications for decision making. Section 6 outlines a research agenda to analyze food catastrophe resilience in order to inform policy decisions. Section 7 concludes.

\section{Global Food Supply Catastrophes}

\subsection{Definitions}

A global catastrophe is, in most general terms, an event causing major harm to global human civilization. More precise definitions have typically been rooted in arbitrary demographics, such as the death of one quarter of the human population (Atkinson 1999) or deaths in the range of $10^{4}$ to $10^{7}$ people (Bostrom and Ćirković 2008). Recently, Baum and Handoh (2014) proposed a resilience definition of global catastrophe, specifically that global catastrophe be defined as an event exceeding the resilience of the global human system, resulting in humanity transitioning to a different and inferior state. The catastrophe could either be a single, global systemic event or a global aggregate of a larger number of related events. ${ }^{5}$ This new state could be human extinction or a diminished survivor population that fails to recover from the catastrophe (Maher and Baum 2013). Of particular concern are scenarios in which recovery never occurs, because then the harm extends into the massive populations of would-be future generations. However, long-term outcomes are beyond the scope of this paper.

Following the resilience definition of global catastrophe, a global food supply catastrophe can be defined as a catastrophe that exceeds humanity's resilience to food supply disruptions, which can in turn be conceptualized in several ways. In physiological terms, the exceedance of food supply resilience results in severe malnutrition with long-term health consequences or even death. In societal terms, the exceedance of food supply resilience results in the affected

\footnotetext{
${ }^{4}$ In other contexts, fossil fuels are considered a primary energy source, and solar energy is an "alternative” energy. However, for agriculture, sunlight is by far the primary energy source, and fossil fuels are an alternative.

${ }^{5}$ The resilience definition of global catastrophe to human systems is adapted from the theory of catastrophe to ecological systems contained in the recently proposed concept of planetary boundaries (Rockström et al. 2009a, 2009b).
} 
Baum, S.D., Denkenberger, D.C., A Pearce, J.M., Robock, A., Winkler, R. Resilience to global food supply catastrophes. Environment, Systems and Decisions 35(2), pp 301-313 (2015). DOI: 10.1007/s10669-015-9549-2

population transitioning to fundamentally different ways of being. The simplest example is when the entire population dies. Another example has the entire population, or a large portion of it, transitioning its labor to food production, resulting in the loss of specialized labor and all the many spectacular goods and services that specialized labor can produce. Indeed, without specialized labor, civilization could not exist. Still another example would see some death from malnutrition, additional death from secondary effects like disease outbreaks, violent conflict over remaining food supplies, and survivor populations assuming different and simpler cultures. ${ }^{6}$

A global food supply catastrophe could be a single, global disruption to food security, such as a volcanic eruption or nuclear war. Or, the catastrophe could a global aggregate of many local disruptions, such as the concurrent depletion of locally dispersed natural resources critical for agriculture. These two types of catastrophes mirror the systemic and aggregative catastrophe types in Baum and Handoh (2014) and Rockström et al. (2009a, 2009b). The prospect of an aggregative global food catastrophe underscores the inherently local nature of food production and consumption. However, local resilience could be important for either type of catastrophe, especially if a systemic global food catastrophe also disrupts transportation systems.

\subsection{Historical Precedent}

The historical record suggests that human populations can indeed be severely harmed by food security catastrophes. Famines in 536-545 (due to severe Northern Hemisphere cooling), 1816 (due to the Mount Tambora eruption), and 1943 (the Bengal famine) were all associated with high mortality, including due to ensuing disease outbreaks (Helfand 2013). Food crises also played a role in the collapse of New Kingdom Egypt (Butzer 2012). Perhaps the most dramatic example is the eruption of the Toba supervolcano, 74,000 years ago in Sumatra. This massive eruption was about 300 times larger than the 1991 eruption of Mt. Pinatubo, the largest eruption of the $20^{\text {th }}$ Century (Robock et al. 2009). The timing of the eruption coincides with an apparent genetic bottleneck in the human population, which has prompted the theory that the eruption caused a major (larger than 50\%) decline in the human population alive at that time (e.g., Ambrose 1998).

The Toba catastrophe theory remains controversial and unresolved. Haslam and Petraglia (2010) showed that the 1000-year glacial period started just before the Toba eruption, disproving the theory that the eruption produced a massive ice advance. Robock et al. (2009) used climate simulations to find a decade-long volcanic winter that could indeed have made the food supply for humans problematic, but Timmreck et al. (2010) found a much smaller climatic response. Lane et al. (2013) found a small climate change averaged over several decades at a lake in Africa following Toba, but this does not support their claim that there could not have been a short-lived, catastrophic volcanic winter (Robock 2014). Petraglia et al. (2007) report archaeological findings of human populations in India above and below the Toba ash layer, suggesting these populations survived Toba. But the archaeological record is scarce, making a definitive conclusion premature.

Suffice it to say, humanity today is quite different than it was during the Toba eruption 74,000 years ago. Today's population is vastly larger and more sophisticated, but it is also less accustomed to living off the land. Out of a total of about 1.4 billion households in the world,

\footnotetext{
${ }^{6}$ Helfand (2013) documents prior food crises resulting in disease outbreaks. Diamond (2005) and Butzer (2012)
} chronicle the collapse of civilizations due to food security disruptions, disease outbreaks, and other stressors. 
Baum, S.D., Denkenberger, D.C., A Pearce, J.M., Robock, A., Winkler, R. Resilience to global food supply catastrophes. Environment, Systems and Decisions 35(2), pp 301-313 (2015). DOI: 10.1007/s10669-015-9549-2

only about 500 million are family farms (Lowderet al. 2014). The rest of the population could struggle severely if global or regional food trade is disrupted. Many farmers will further depend on imported resource inputs, such as fuel and fertilizer. And of course farmers depend on sunlight and favorable temperatures, which could be disrupted by the catastrophe. The dominant position human civilization has taken on Earth may be fragile.

\subsection{Contemporary Risk}

Supervolcano eruptions at the scale of Toba are rare events, occurring approximately once every 100,000 years (Mason 2004). Comparably devastating asteroid impacts are estimated to be two to five times more rare (Rampino 2002; Sparks et al. 2005). Nuclear war appears to be more probable. The probability of nuclear war per unit time is harder to estimate due to lack of historical data and constantly changing geopolitical circumstances, among other factors. To our knowledge, no rigorous estimates for the total probability of nuclear war exist. Hellman (2008) estimates the probability of nuclear war between the United States and Russia due to crises similar to the Cuban missile crisis, finding the probability to lie in the range of $2 \times 10^{-4}$ to $5 \times 10^{-3}$ per year. Barrett et al. (2013) estimate the probability of inadvertent nuclear war $^{7}$ between the US and Russia, finding a range of probability estimates, $90 \%$ of which fall between $2 \times 10^{-4}$ and 0.07 per year if launch can occur at any time, or between $10^{-5}$ and 0.05 per year if launch can only occur during a Russia-US crisis. These studies only consider one type of nuclear war between one pair of countries. The total probability across all types of nuclear war and all pairs of countries will be larger. Estimates for the total probability of nuclear war on the order of $10^{-4}$ to 0.01 per year are reasonable, making nuclear war significantly more probable than comparably severe asteroid or comet impacts or supervolcano eruptions.

The effects of a nuclear war, asteroid or comet impact, or supervolcano eruption are all most severe during the first few years, when atmospheric particulate matter is most concentrated. The particles then gradually dissipate out of the atmosphere, and sunlight returns to normal. Recent climate simulations indicate that smaller but significant cooling will persist even one or two decades following the initial event (e.g., Robock et al. 2007; Mills et al. 2014). Food supplies would need to be maintained throughout this period.

Nuclear war, asteroid and comet impacts, and supervolcano eruptions are all relatively well characterized as threats to global food supplies. The mechanism is straightforward: they put particles into the atmosphere, blocking incoming sunlight. In contrast, other threats are less well characterized. The rapid increase in surface temperatures following from the abrupt cessation of stratospheric geoengineering would undoubtedly disrupt agriculture, with the severity of the disruption dependent on the geoengineering scenario; for a given scenario, it is not presently clear how severe the disruption would be. It is likewise difficult to characterize the probability of the abrupt cessation of stratospheric geoengineering. Indeed, it is not presently known whether stratospheric geoengineering will be commenced in the first place. Similar uncertainty surrounds abrupt climate change that could occur without geoengineering, as well as threats from plant pathogens and invasive species (natural or engineered). And there remains the possibility of agriculture disruption from presently unknown or poorly known threats.

\footnotetext{
${ }^{7}$ Inadvertent nuclear war as defined by Barrett et al. (2013) occurs when one side misinterprets a false alarm as a real attack and launches nuclear weapons in what it believes is a counterattack, but is in fact a first strike.
} 
Baum, S.D., Denkenberger, D.C., A Pearce, J.M., Robock, A., Winkler, R. Resilience to global food supply catastrophes. Environment, Systems and Decisions 35(2), pp 301-313 (2015). DOI: 10.1007/s10669-015-9549-2

\section{Food Supply Options}

In the face of such uncertain threats, increasing a system's resilience has been recommended as a policy response (Park et al. 2013; Linkov et al. 2014). A resilient system can withstand a wide range of threats, regardless of these threats' exact nature, probability, and severity. For threats to food security, increased resilience would mean increased ability to maintain food security across a wide range of food-related disruptions. At least three types of options are available for maintaining food supplies: stockpiles, traditional agriculture, and alternative foods.

\subsection{Food Stockpiles}

Food stockpiles are perhaps the most obvious and most commonly made proposal for increasing resilience to food supply disruptions. Schneider (1976) refers to this as the Genesis Strategy, in reference to a Book of Genesis story. Joseph warns the Pharaoh that seven years of feast will be followed by seven years of famine, and so food should be stockpiled during years one to seven as reserves for years eight to fourteen. By analogy, Schneider argues for similar stockpiles to provide "margins of safety" in response to modern threats to human survival. More recently, Maher and Baum (2013) proposed stockpiles of food and other critical resources as a means of increasing resilience to global catastrophes.

Public and private sector food stockpiles are widespread throughout the world. President Franklin D. Roosevelt created a grain reserve during the Great Depression, which was ended by the 1996 Freedom to Farm Act in the spirit of deregulation (Kaufman 2012). In the private sector, many households contain food stockpiles of varying sizes and sophistication. The Church of Latter Day Saints instructs its members to build up to a year supply of food for their families (Parrett 2012). Many "preppers” and survivalists also maintain extensive household stockpiles. Several companies offer ready-made food stockpiles, catering to this market demand. Worldwide, existing food stockpiles could support human populations for around four to seven months (Do et al. 2010; Denkenberger and Pearce 2014).

Food stockpiles can provide an important food option in the aftermath of a variety of catastrophes. Food stockpiles are especially attractive if they can be accessed in the immediate aftermath, when other options are most difficult to come by. Food stockpiles can be locally distributed and thus accessible even if transportation systems are not operational. And food stockpiles require little specialized training, as evidenced by the many lay people who maintain their own stockpiles. All this suggests a significant role for food stockpiles in increasing resilience to food security catastrophes, including both local and global catastrophes.

However, food stockpiles come with significant downsides. Above all, they are expensive to pre-catastrophe populations. Food diverted to stockpiles can reduce the food available to precatastrophe populations. This effect can be lessened by taking food back from stockpiles to immediate consumption after it has been in the stockpile for some length of time. But even with such a system in place, food stockpiles could still worsen pre-catastrophe food security, especially if the stockpiles are built up quickly. Given that hunger and malnutrition remain significant problems worldwide, with about 805 million people not having enough food to lead a healthy active life (World Food Programme 2014), this makes for an important downside.

Furthermore, there are limits to how much food can be stockpiled. Catastrophes like nuclear and volcanic winter could disrupt global food supplies for years or even decades. It may be outright infeasible to produce food stockpiles that could feed the global human population for 
Baum, S.D., Denkenberger, D.C., A Pearce, J.M., Robock, A., Winkler, R. Resilience to global food supply catastrophes. Environment, Systems and Decisions 35(2), pp 301-313 (2015). DOI: 10.1007/s10669-015-9549-2

such long periods. Food stockpiles can be at most a partial solution to increasing resilience to global food security catastrophes.

\subsection{Agriculture}

Global food supply catastrophes will diminish agriculture, but they will not necessarily render agriculture impossible. When agriculture is possible, it can make an important contribution to food supplies. Post-catastrophe growing conditions will often be altered, in which case it will be accordingly important to adjust the selection of crops and other growing practices. With sufficient planning and adaptation, agriculture can increase resilience to global food supply catastrophes.

Modern crop models can be used to study the prospects for agriculture. For example, the Decision Support System for Agrotechnology Transfer (DSSAT) crop model (Jones et al. 2003) has been used to simulate crop responses in China to the climate changes in the years following nuclear war (Xia and Robock 2013; Xia et al. 2015) and geoengineering (Xia et al. 2014b). Such modeling can help determine when and where crops will be able to be grown again, and what adaptation measures (changing crops, planting dates, fertilizer, irrigation) will be possible during the years that the Earth warms back up.

A large nuclear war between the US and Russia, even with today's arsenals, can produce a nuclear winter, with temperatures plummeting below freezing for an entire year or two in agricultural regions (Robock et al. 2007a; Toon et al. 2008). This would essentially stop agricultural production for a year globally, and those with food would certainly not trade it. As the planet warmed gradually as smoke from the fires gradually settled out of the atmosphere, some types of agriculture would be possible, but under drastically altered situations, because the climate effects would last for more than a decade. To ensure survival, a decade's worth of food supply would be needed.

Even a "small” nuclear war, with 100 15-kiloton weapons, could produce climate change unprecedented in recorded human history. For comparison, there are currently around 16,000 total nuclear weapons worldwide, most of which have yields larger than 15 kilotons. Crop simulations indicate that agriculture production in the US and China (the two largest agricultural producers in the world) would fall by $15 \%$ to $40 \%$ for the first five years and $10-25 \%$ for the next five years (Table 1). If these results are representative of the entire world, food trade would be disrupted and major food shortfalls could persist for a decade or more. For scenarios intermediate between the two above, proportional food disruptions could occur.

For this sort of partial agriculture disruption, resilience can be increased by shifting crop output to more efficiently feed people. Large and growing portions of human-edible crops are used for livestock feed and biofuels. Cassidy et al. (2013) estimate that shifting crops to direct human consumption could bring 70\% more food calories globally, enough to feed four billion more people, with the US alone able to feed one billion more people. These numbers are for crops only and do not factor in pasture-fed livestock or aquaculture. The numbers are also for agriculture under normal circumstances and may not apply exactly to food catastrophe scenarios, but they nonetheless indicate the significant potential for shifting crop use. Following a catastrophe, market pressures could induce some of this shift without an intentional human intervention, but dedicated policy measures could enhance the shift to increase resilience and keep more people alive. 
Baum, S.D., Denkenberger, D.C., A Pearce, J.M., Robock, A., Winkler, R. Resilience to global food supply catastrophes. Environment, Systems and Decisions 35(2), pp 301-313 (2015). DOI: 10.1007/s10669-015-9549-2

Table 1. Changes of agricultural productivity in the decade following a nuclear war between India and Pakistan using 100 nuclear weapons (Robock et al. 2007b, Mills et al. 2014) as simulated by agricultural production models (Özdoğan et al. 2013, Xia and Robock 2013, Xia et al. 2015).

\begin{tabular}{|l|c|c|}
\hline & First 5 years & Second 5 years \\
\hline US maize & $-20 \%$ & $-10 \%$ \\
\hline US soybeans & $-15 \%$ & $-10 \%$ \\
\hline China maize & $-20 \%$ & $-15 \%$ \\
\hline China middle season rice & $-20 \%$ & $-15 \%$ \\
\hline China spring wheat & $-35 \%$ & $-25 \%$ \\
\hline China winter wheat & $-40 \%$ & $-25 \%$ \\
\hline
\end{tabular}

In summary, agriculture can remain partially viable during some global food supply catastrophes, but it would not be enough to prevent massive food insecurity. Furthermore, the disruption to agriculture could last for many years. Meanwhile, current food stockpiles offer less than one year of food. This suggests the need for other options to enhance resilience to global food supply catastrophes.

\subsection{Alternative Foods}

Food can potentially be produced as long as there are available sources of energy and other critical resources. In the absence of adequate sunlight, alternative energy sources are needed. Two major alternative energy sources are biomass and fossil fuels. Biomass includes trees and other plants, whose energy can be entered into the food chain. Fossil fuels could in principle be any of coal, oil, and natural gas, though in practice only the latter is particularly viable.

Denkenberger and Pearce (2014; 2015) identify, design, and evaluate alternative food options suitable for post-catastrophe environments. Figure 1 diagrams select food sources and energy flows for alternative foods. The diagram shows food flows to both humans and preserved species, noting that the same foods that keep humans alive could also help preserve certain endangered species. As Figure 1 suggests, alternative food production is optimized when multiple food sources are produced together, because the wastes from some foods can become energy and resource sources for other foods. Here is an overview of these alternative foods:

- Wood can be fed to mushrooms or beetles, which can be fed to livestock or directly to humans. For optimal conversion efficiency, trees should be chopped down and chipped.

- $\quad$ Other human-inedible plants and other tree parts including leaves and barks can be fed to mushrooms, to livestock animals, and in some cases to humans directly. For example, teas can be made from leaves, which offer humans some nutrition.

- $\quad$ Natural gas can feed certain bacteria, which can in turn be fed to animals. This process is already in commercial production for livestock feed (Unibio 2014) and could be adapted as a direct human food source. 
Baum, S.D., Denkenberger, D.C., A Pearce, J.M., Robock, A., Winkler, R. Resilience to global food supply catastrophes. Environment, Systems and Decisions 35(2), pp 301-313 (2015). DOI: 10.1007/s10669-015-9549-2

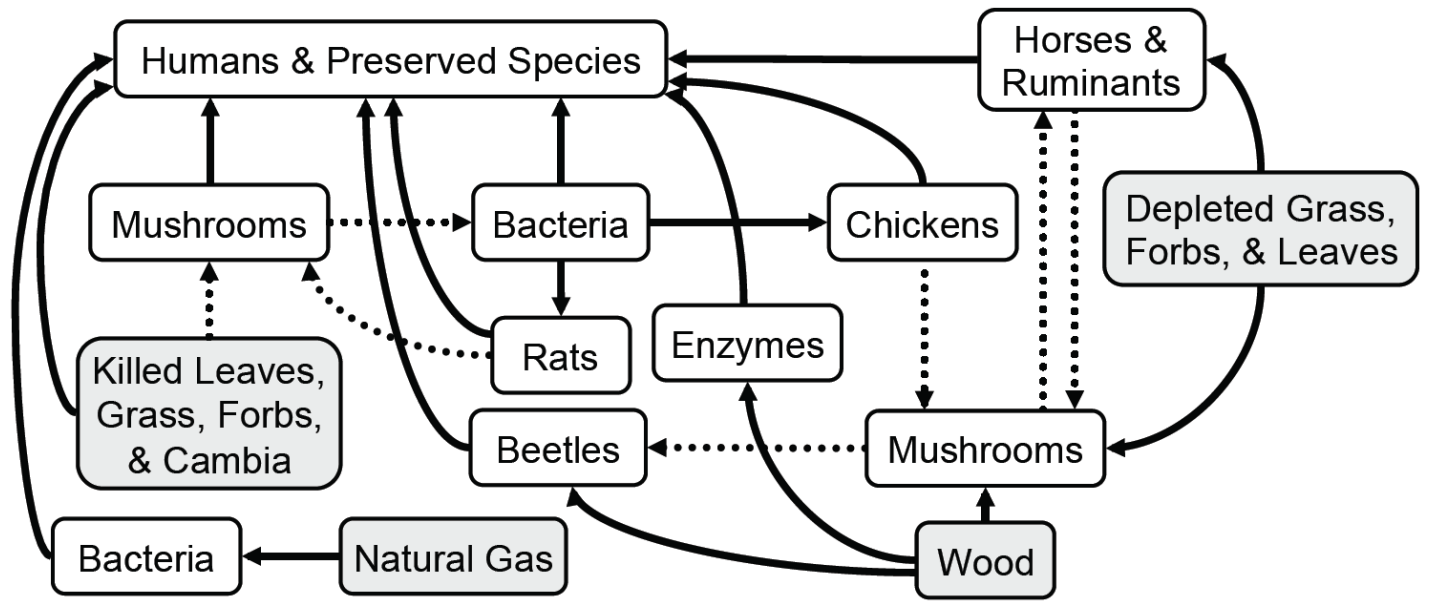

Figure 1. Select food sources and energy flows for alternative foods. Cambia are inner barks and forbs are non-woody, non-grass plants. Solid lines are food. Dotted lines are waste. Shaded blocks are source resources.

Since these alternative food processes are not already in large-scale production, they would need to be scaled up quickly to meet post-catastrophe food demand. How quickly alternative foods would need to be scaled up depends on how severely agriculture is disrupted and how much food has been stockpiled. The need to quickly scale up alternative food production means that faster-scaling foods will often be preferable. For example, rabbits can eat the same biomass as cows but reproduce faster. Shipworms (a saltwater clam) can digest wood and can have millions of eggs over a lifecycle that lasts several months (Ho 2012). While shipworms are typically considered a pest, in the post-supereruption environment they could become a valuable component of the food supply. Similarly, termites have significant initial stock and can digest cellulose very well. While termites are difficult to raise in captivity (Leuthold et al. 2004), they can live in houses. Rabbits, shipworms, and termites all can be fed biomass and thus could be attractive, rapid-scaling alternative foods. Figure 2 shows scaling rates for three alternative foods analyzed in Denkenberger and Pearce (2014).

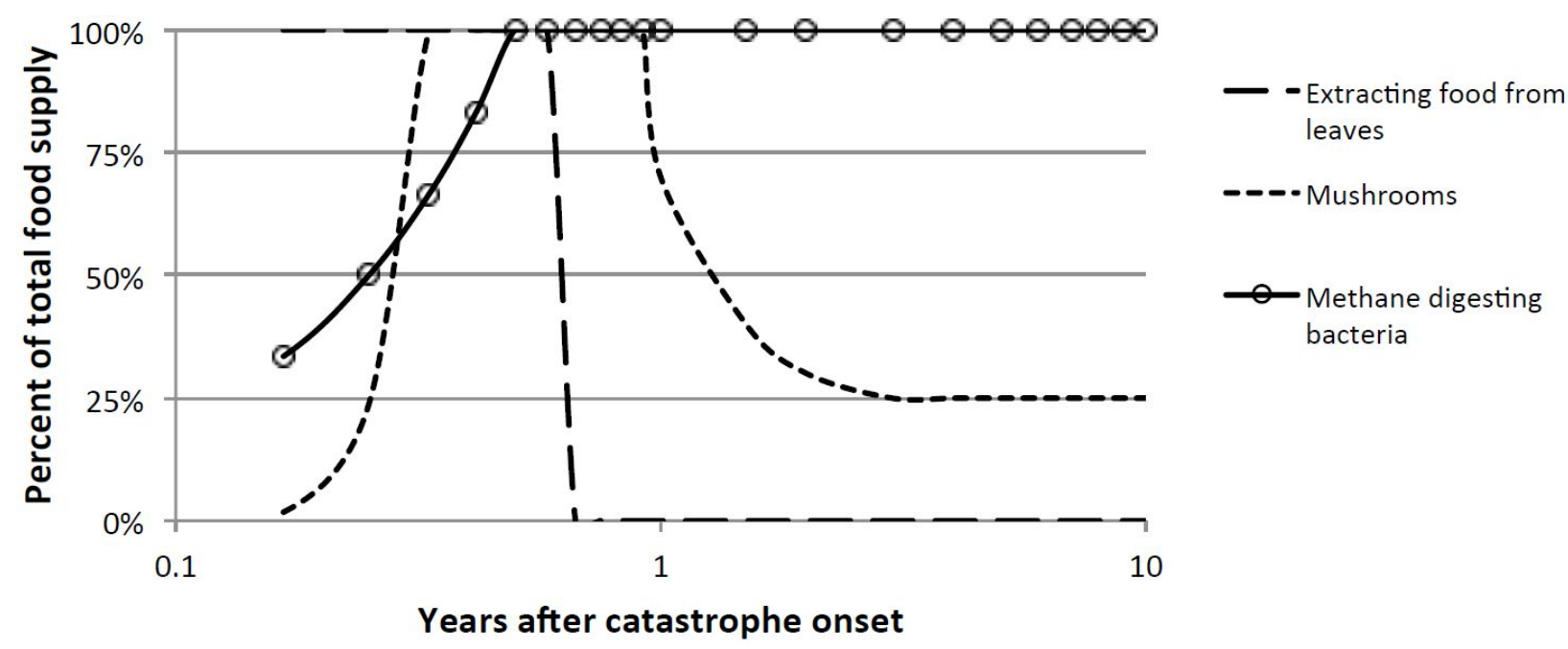


Baum, S.D., Denkenberger, D.C., A Pearce, J.M., Robock, A., Winkler, R. Resilience to global food supply catastrophes. Environment, Systems and Decisions 35(2), pp 301-313 (2015). DOI: 10.1007/s10669-015-9549-2

Figure 2. Scaling rates showing approximate food supply over time from three alternative food sources and stored food. Adapted from Denkenberger and Pearce (2014).

One potential downside to alternative foods is social acceptability. ${ }^{8}$ While some of the foods produced through alternative processes are already in common consumption, others are not. Postcatastrophe populations may resist eating these "weird" foods. This effect may be attenuated by the desperate post-catastrophe circumstances. However, to the extent that alternative food consumption is resisted, their social acceptability could significantly diminish their overall potential for increasing food security. Alternative food research, development and deployment (RD\&D) should make social acceptability a central concern and structure food choices accordingly.

\subsection{Comparison of the Three Food Supply Options}

The three food supply options each have certain advantages and disadvantages. Relative to food stockpiles, alternative foods can be vastly less expensive to pre-catastrophe populations. The main expense associated with alternative foods is the cost of further RD\&D of alternative food practices. Given that some alternative foods are already in common production, RD\&D expenses should not be exorbitant. Furthermore, as alternative foods can be shifted into production in the aftermath of catastrophe, they do not require harming pre-catastrophe food security. These advantages suggest that, to the extent possible, post-catastrophe food security should emphasize alternative foods over food stockpiles. If alternative food production would be viable postcatastrophe, the primary role for food stockpiles should be as a temporary stopgap measure while alternative food production is scaled up.

Relative to agriculture, the core advantage of alternative foods is that they can be produced even when sunlight is blocked, as occurs in several catastrophe scenarios. However, alternative foods require the large-scale depletion of stored energy reserves in the form of either biomass or fossil fuels. Depleting biomass reserves means chopping down trees and other plants. Depleting fossil fuel reserves means consuming natural gas faster than would otherwise occur. Both of these depletions are undesirable for a variety of ecological and economic reasons. While traditional sunlight-based agriculture has its own ecological and economic harms, these will generally be less than those of alternative foods, because there is minimal harm associated with consuming sunlight. Therefore, alternative foods should in general be used only during times when agriculture is insufficient.

Pulling these insights together, we find that agriculture should in general be used as the first option, alternative foods as the second option, and food stockpiles as the third option. For a given food catastrophe scenario, the amount of food stockpile required can be calculated by modeling the dynamics of agriculture disruption and alternative foods scale-up and seeing what gaps are left. These general findings may have exceptions under specific scenarios.

\section{Increasing Local Resilience}

Food production from either traditional agriculture or alternative processes requires a variety of input resources. Following a catastrophe, transportation could be significantly impaired, forcing

\footnotetext{
${ }^{8}$ Similar issues of social acceptability can be found for many technological solutions to societal risks (e.g., Flynn et al. 1992; Otway and Von Winterfeldt 1982).
} 
regions to rely on local resources. But there is an uneven geographic distribution of both the resources and the populations that will depend on them. This means that resilience to global food security catastrophes may be needed at local scales, and furthermore that efforts to increase resilience may need to be customized to local circumstances.

As a simple illustration of geographic disparities in resources and population, consider the continental US. Figure 3 shows the continental US population density per the 2010 census. Figure 4 shows concentrations of live tree biomass on timberland per 2007 US Forest Service data; live tree biomass is an input resource for alternative foods.

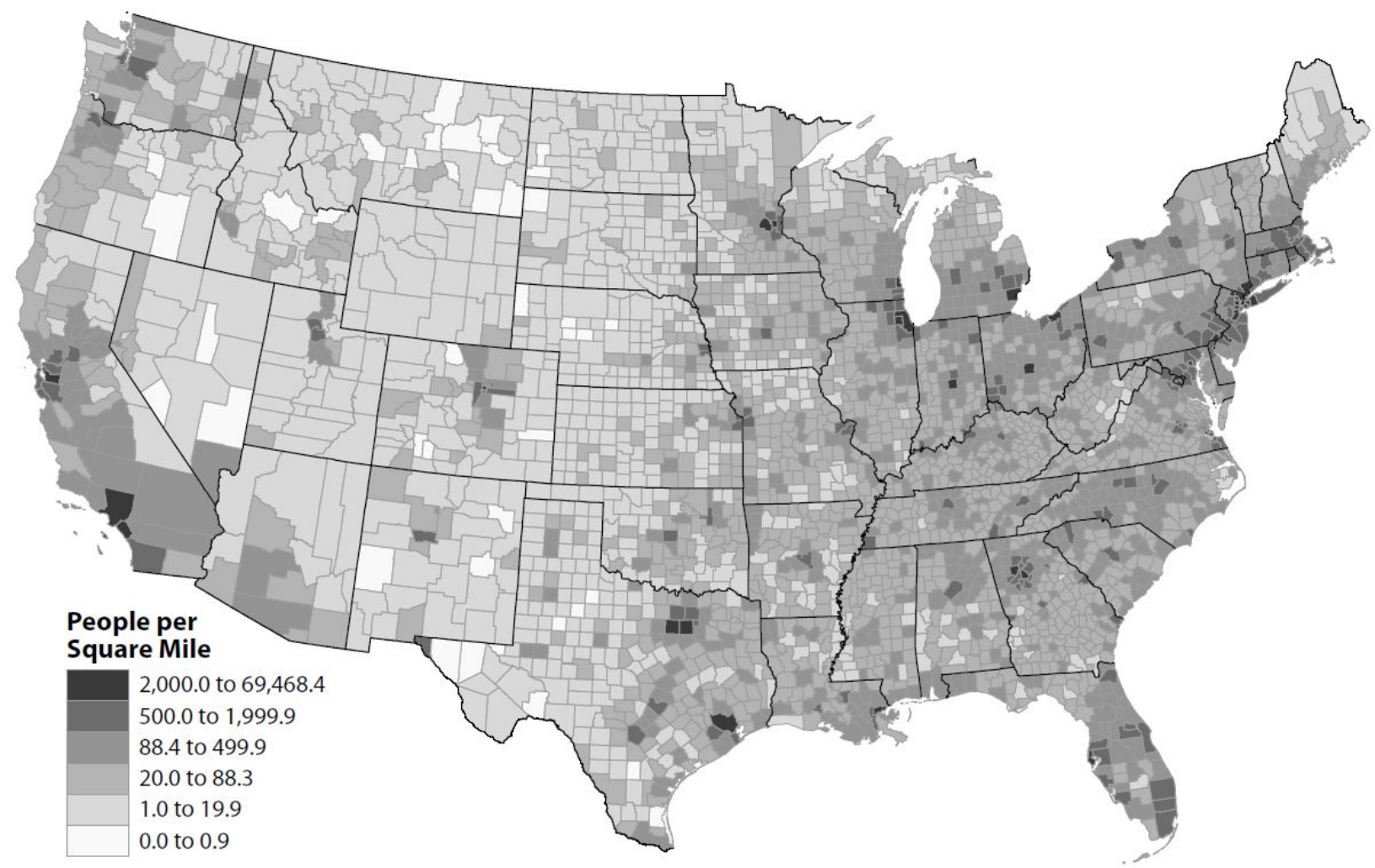

Figure 3. Population density of the continental US. Data is from the 2010 census. The figure is adapted from a map "2010 Census Results - United States and Puerto Rico: Population Density by County or County Equivalent” published by the US Census Bureau, http://www.census.gov/geo/maps-data/maps/pdfs/thematic/us_popdensity_2010map.pdf. 
Baum, S.D., Denkenberger, D.C., A Pearce, J.M., Robock, A., Winkler, R. Resilience to global food supply catastrophes. Environment, Systems and Decisions 35(2), pp 301-313 (2015). DOI: 10.1007/s10669-015-9549-2

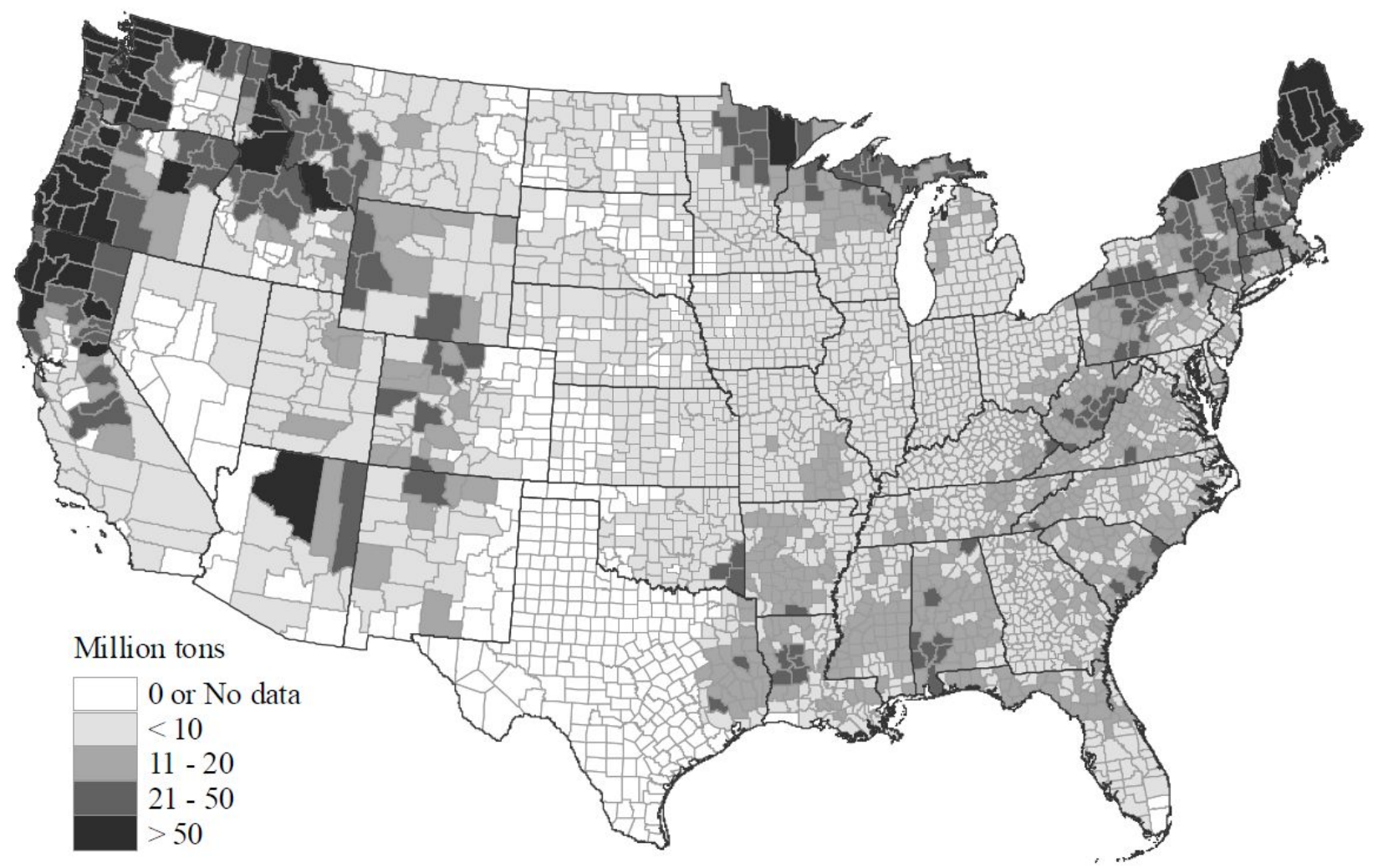

Figure 4. Concentrations of live tree biomass on timberland in the continental US. Data is from the National Inventory and Analysis National Program conducted in 2007 by the US Forest Service. The figure is adapted from a map "All Live Tree Biomass on Timberland, 2007” published by the US Forest Service, http://www.fia.fs.fed.us/toolsdata/maps/2007/descr/livebio.asp.

A comparison of these two maps shows that live tree biomass is sometimes, but not always, concentrated in the same locations as human populations. For example, the Pacific Northwest has abundant live tree biomass, including in the immediate vicinities of the Seattle and Portland metropolitan areas. Many thinly forested regions, such as Nevada or the Texas panhandle, are also thinly populated. Populations in these areas may be able to rely on live tree biomass for post-catastrophe food security, either because live tree biomass concentrations are sufficiently large or population densities are sufficiently small. Likewise, efforts to increase local resilience to global food supply catastrophes in these regions should emphasize means of producing food from live tree biomass. However, live tree biomass will be most effective in heavily forested areas that are thinly populated, such as northern Maine or the Upper Peninsula of Michigan. And live tree biomass will be least effective in heavily populated areas that are thinly forested, such as the Dallas and Los Angeles metropolitan areas.

The importance of local resilience underscores the need for increasing resilience systemically. Focusing on a single metric like the quantity of food available is not enough. Other factors, such as distribution networks, are also necessary. If pre-catastrophe distribution networks remain intact, then food could be transported from places with an abundance to places with a need. For example, food from live tree biomass could be transported from the Upper Peninsula 
Baum, S.D., Denkenberger, D.C., A Pearce, J.M., Robock, A., Winkler, R. Resilience to global food supply catastrophes. Environment, Systems and Decisions 35(2), pp 301-313 (2015). DOI: 10.1007/s10669-015-9549-2

of Michigan to the Dallas metropolitan area, or at least to the Chicago or Detroit metropolitan areas. Economic systems are also important. Hunger and malnutrition today is often driven by or worsened by poverty (Dreze et al. 1995). Post-catastrophe economies could be significantly disrupted, leaving additional people unable to purchase or barter for food. Location-specific policies to increase resilience to food supply catastrophes should take these factors into account.

\section{Implications for Decision Making}

While systemic factors are important to post-catastrophe food security, they are also harder to analyze, especially given the lack of research on post-catastrophe conditions (Maher and Baum 2013) and the lack of systemic research on global catastrophes in general (Baum et al. 2013). Thus, as a first-order decision criterion, consider the goal of maximizing resilience to global food supply catastrophes, with resilience measured in terms of the food supply available relative to the food demand:

$$
R=\frac{F_{s}}{F_{d}}=\frac{S t+A g+A F}{\rho \times e_{r}}
$$

Here resilience $(R)$ [unitless] is defined as food supply $\left(F_{s}\right)$ [calories (cal)] divided by food demand $\left(F_{d}\right)$ [cal]. Food supply is from food stockpiles $(\mathrm{St})$ [cal], agriculture $(\mathrm{Ag})$ [cal], and alternative foods $(A F)$ [cal]. Food demand is the product of population $(\rho)$ [people] and the food energy required per person $\left(e_{r}\right)$ [cal/person]. Per this formulation, food security is achieved whenever $R \geq 1$, i.e. whenever food supply meets or exceeds food demand.

Equation 1 shows static, aspatial variables. However, the variables are all functions of both time and space. The temporal and spatial dimensions have different implications for decisionmaking. If, at some time $t_{1}$, for some population $\rho_{a}, R_{a}\left(t_{1}\right)<1$, then the members of this population may die. And if they die, then $R_{a}\left(t_{2}\right)$ does not matter, for any $t_{1}<t_{2}$. For this reason, if there is not enough food to keep everyone alive for the duration of the catastrophe, then it would not be optimal to distribute food uniformly across the population. A uniform distribution would ensure that nobody has enough to survive and everyone dies. Some sort of lifeboat ethics (Hardin 1974) is warranted, in which resources are distributed unevenly to increase the survivor population.

The importance of maintaining $R_{a}(t) \geq 1$ for all $t$ has implications for the selection of food options. As discussed in Section 3, agriculture may be unavailable or insufficiently available for multiple years of a long-duration catastrophe such as a nuclear or volcanic winter. Food stockpiles can be made available at any time, but they will in general not be able to last for the entirety of a long-duration catastrophe. Alternative foods can last longer, but may take months or years to scale up (Figure 2) and can require resource inputs that are not available in all locations. The amounts of food that can be produced by each of the three methods will vary depending on the resources available in a given region and as a function of time (e.g. the food supply varies between summer and winter and is influenced by acute events such as droughts). Each region should consider its available resources and craft a food security plan accordingly. Regions with fewer resources for alternative foods or less capacity for agriculture relative to their populations may need to invest more heavily in food stockpiles.

Given the possibility that not everyone can be kept alive, the goal of maximizing resilience to global food security catastrophes can be expressed as maximizing the size of the population that survives the catastrophe. This can be achieved by ensuring, throughout the duration of the 
Baum, S.D., Denkenberger, D.C., A Pearce, J.M., Robock, A., Winkler, R. Resilience to global food supply catastrophes. Environment, Systems and Decisions 35(2), pp 301-313 (2015). DOI: 10.1007/s10669-015-9549-2

catastrophe, $R=1$ for all survivor populations and $R=0$ for those who will die. Following this procedure prevents food from being wasted on people who will survive anyway or people who will die anyway, thereby maximizing the survivor population. This formulation assumes that food can be readily transferred from person to person, an assumption that will not hold if transportation is curtailed by the catastrophe. ${ }^{9}$ It also assumes that no margin of safety is needed for survivors, i.e., that having $R=1$ will never result in failure due to imperfections in allocations; this assumption will also not in general hold. And so the optimal food allocation may sometimes have $R \neq 1$ and $R \neq 0$, but the underlying logic of not wasting food on survivors or nonsurvivors remains the same.

Alternatively, it may be possible to keep everyone alive. Denkenberger and Pearce (2014; 2015) argue that alternative food processes can produce enough food to keep everyone alive throughout a variety of global catastrophes lasting up to five years with no conventional agriculture. Opportunities to invest heavily in food stockpiles prior to catastrophes would further suggest that everyone could be kept alive. In this case, resilience to global food security catastrophes is maximized when some function of $R$ is maximized. Several possibilities for this function are plausible:

- $\quad$ The total value of $R$ integrated across all people and all time. This corresponds to maximizing the total global food supply across the duration of the catastrophe. This simple criterion is indifferent to the distribution of food across people and time and is thus at best a crude approximation of the optimal food program. It is also analogous to the issue of maximizing monetary benefits or gross domestic product without respect to distribution (on which see e.g. Adler and Posner 2006).

- $\quad$ The maximin of $R$ across people and time. This would maximize the minimum value of $R$ that any person ever experiences across the duration of the catastrophe. With enough food for everyone, this ensures that everyone survives and that everyone has at least the maximum possible margin of safety $\left(F_{s}-F_{d}\right)$ that can be shared by all people, thereby maximizing the probability that no one dies from food insecurity. However, the maximin criterion can be criticized as insensitive to anything other than the minimum value (e.g., Harsanyi 1975).

- $\quad$ The allocation of food that achieves some threshold $R_{x}>1$ for the maximum number of people, with the remaining food distributed in any particular fashion. This permits a margin of safety. Given sufficient food supply, the margin of safety can be increased. Such a margin of safety is analogous to the Baum and Handoh (2014) suggestion of keeping threats a safe distance from any thresholds that, if crossed, would exceed the global human system's resilience, resulting in a global catastrophe.

- $\quad$ The maximin of $R$ for a specific subset of the population. The long-term survival of civilization does not require that everyone survive a catastrophe. Choosing the maximin of $R$ for a subset population could maximize the probability that the survivor population is sufficient for the long-term survival of civilization. As such this criterion may be at least partially consistent with calls for using the decision criterion of minimizing global catastrophic risk (e.g., Bostrom 2002). ${ }^{10}$

\footnotetext{
${ }^{9}$ Indeed, this assumption often does not hold under normal times, as food transfers often result in some food loss.

${ }^{10}$ Bostrom (2002) uses the term existential risk instead of global catastrophic risk but the underlying concept is essentially the same.
} 
Baum, S.D., Denkenberger, D.C., A Pearce, J.M., Robock, A., Winkler, R. Resilience to global food supply catastrophes. Environment, Systems and Decisions 35(2), pp 301-313 (2015). DOI: 10.1007/s10669-015-9549-2

The discussion thus far, while somewhat simplistic, provides a general picture of how to maximize resilience to global food security catastrophes. But maximizing resilience to global food security catastrophes is not actually a good decision criterion. Food security is not the only factor in global catastrophic risk, and global catastrophic risk may not be the only important societal issue. ${ }^{11}$ Investments in resilience to global food security catastrophes come at a cost of lost opportunity to invest in other objectives.

The opportunity cost of food resilience investments is especially clear for food stockpile decisions. A virtually unlimited quantity of money could be invested in maximizing food stockpile size, at massive opportunity cost. It is utterly implausible that maximizing food stockpile size could ever be optimal for society. But it will generally also not be optimal to maximize food production from agricultural or alternative food processes.

There is a more general point to be made here about decision-making regarding resilience: maximizing resilience will in general not be a good decision criterion. This point stands in contrast with recent calls to prioritize increasing resilience in the face of uncertain and catastrophic threats such as global food supply catastrophes (Linkov et al. 2014; Park et al. 2013). The simple reason for this point is that increasing resilience is not the only means of improving the world, and maximizing resilience will in general come at the expense of these other means. Any reasonable decision criterion, whether it is maximizing expected value or something else, will permit an optimal portfolio of actions that includes some effort to increase resilience but also other efforts, including efforts to prevent catastrophes or other disruptions from happening in the first place. That said, increasing resilience remains an attractive component to a broader portfolio of responses to reducing global food supply catastrophe risks, alongside efforts to reduce the probabilities of these catastrophes. Food supply resilience is especially attractive given the broad range of known and possible unknown global food supply threats.

\section{Analysis of Food Supply Catastrophe Policy: A Research Agenda}

What should the world's policy be for increasing resilience to global food supply catastrophes? What should specific local communities’ policies be? Answers to these questions must stem from analysis of catastrophe scenarios as well as normative considerations about decision criteria. Key issues include:

- What are the probabilities of specific catastrophe scenarios? Section 2.3 describes some probabilities, but significant gaps in the literature remain.

- $\quad$ How effective are the available food supply options for increasing resilience to these catastrophes? Section 3 surveys the options and Section 4 discusses location-specific factors, but more detail is needed to reach conclusions about food supply policy. How much food could each option produce in a given catastrophe scenario? How effectively could the food be distributed to people in need?

- How resilient is human society to food catastrophes? Answering this question requires both the physiology of malnourishment and the sociology of food-stressed populations.

\footnotetext{
${ }^{11}$ An argument can actually be made that society at present should prioritize the minimization of global catastrophic risk above all other objectives, given the massive harms of global catastrophes to future generations (see for example Bostrom 2002; Beckstead 2013). But there is no universal consensus on this matter, and so other objectives may be worth pursuing.
} 
Baum, S.D., Denkenberger, D.C., A Pearce, J.M., Robock, A., Winkler, R. Resilience to global food supply catastrophes. Environment, Systems and Decisions 35(2), pp 301-313 (2015). DOI: 10.1007/s10669-015-9549-2

- $\quad$ How much would it cost to procure various degrees of food supply resilience? Answering this question requires economic details of the food supply options.

- How should food supply resilience be defined and incorporated into decision criteria?

Section 5 discusses some possible answers to this question.

- $\quad$ Finally, how much food supply resilience should be procured? Answering this question requires a synthesis of all of the above questions.

A dedicated food supply resilience research program is needed to rigorously answer these questions, especially the questions about food supply resilience. Questions about the probability of catastrophe scenarios and the normative status of resilience in decision criteria are of broader interest and thus may be answered in the context of other research. Here is an illustrative sketch of some of the analysis a food supply resilience research program should conduct in order to inform policy decisions.

Let us assume an annual food supply boundary $F_{B}$ defined as the minimum food supply $F_{S}$ necessary to achieve food security. ${ }^{12} F_{B}$ is set according to some normative principle, such as those outlined in Section 5, and can likewise depend on such factors as the pre-catastrophe population, the minimum population needed for long-term human survival, cost factors, catastrophic risk, and society's tolerance for catastrophic risk. Food supply resilience requires that the food supply $F_{S}$ be greater than or equal to $F_{B}$ at all times. Achieving $F_{S} \geq F_{B}$ at all times requires a dynamic evaluation of catastrophe scenarios and society's ability to supply food in response.

Consider a hypothetical food catastrophe scenario that reduces global agricultural productivity to $25 \%$ of $F_{B}$ immediately following the catastrophe and gradually returns agricultural productivity to normal (with productivity 125\% of $F_{B}$ ) over the following 20 years. Recall from Section 3.4 that agriculture will in general be the first choice food supply, followed by alternative foods, followed by food stockpiles. Thus, following the catastrophe, alternative food would first be scaled up as quickly as possible to meet the agriculture shortage and then scaled back down as agriculture picks back up. Food stockpiles would be consumed only at the beginning as alternative foods are scaled up. This hypothetical scenario is shown in Figure 5.

The required food stockpile can be calculated from the data shown in Figure 5. Agricultural productivity increases linearly with $5 \%$ of $F_{B}$ added each year. Alternative food scales up to 35\% after one year. By the second year, alternative food scales up to produce more food than is needed, so it produces exactly the difference between $F_{B}$ and agricultural productivity. This ensures that $F_{B}$ is reached without excessively diminishing the natural resource inputs to alternative foods (such as biomass and natural gas). Finally, food stockpiles make up the difference over the first two years while alternative food scales up. Integrating the alternative food and food stockpile curves over time shows that this scenario uses alternative food amounting to $490 \%$ of $F_{B}$ and food stockpiles amounting to $110 \%$ of $F_{B}$. Since $F_{B}$ is an annual food supply, the pre-catastrophe food stockpile purchase would amount to slightly more than one year of food supply. This exceeds the current world food stockpiles of four to seven months. If $F_{B}$ is a supply sufficient to keep the entire world population alive, then stockpiles would need to

\footnotetext{
${ }^{12}$ The use of "boundary" here is in the spirit of planetary boundaries research (Rockström et al. 2009a, 2009b; Baum and Handoh 2014), in which boundaries are normative policy parameters set a safe distance away from dangerous system thresholds. Here, achieving $F_{S} \geq F_{B}$ ensures a sufficiently small probability that food security thresholds will be crossed-a sufficiently small probability that humanity's resilience to food catastrophes will be exceeded.
} 
Baum, S.D., Denkenberger, D.C., A Pearce, J.M., Robock, A., Winkler, R. Resilience to global food supply catastrophes. Environment, Systems and Decisions 35(2), pp 301-313 (2015). DOI: 10.1007/s10669-015-9549-2

be approximately doubled to achieve food supply resilience to this hypothetical catastrophe scenario. Thus even with alternative foods, achieving food supply resilience would require an expensive investment in food stockpiles.

Suppose alternative foods are not available at all. After all, alternative foods are a new and untested concept. Additional RD\&D would be needed before society could count on alternative food performance as shown in Figure 5. In the absence of alternative foods, their contribution to the food supply would need to be made up for with an increased food stockpile, amounting in total to $600 \%$ of $F_{B}$, or six full years of food supply. This is approximately 12 times the current food stockpile. Alternative foods thus cut the required food stockpile by about five full years. While this is only a result from a hypothetical scenario, it speaks to the high value that an alternative food RD\&D program could have.

The analysis presented here is intended only to illustrate some of the analysis that a food supply resilience research program could do. The results obtained have no policy significance. Furthermore, the analysis presented here is only a stylized example. A full research program should consider important details including local variation in food production, food transport capacity, and uncertainty in all of the parameters.

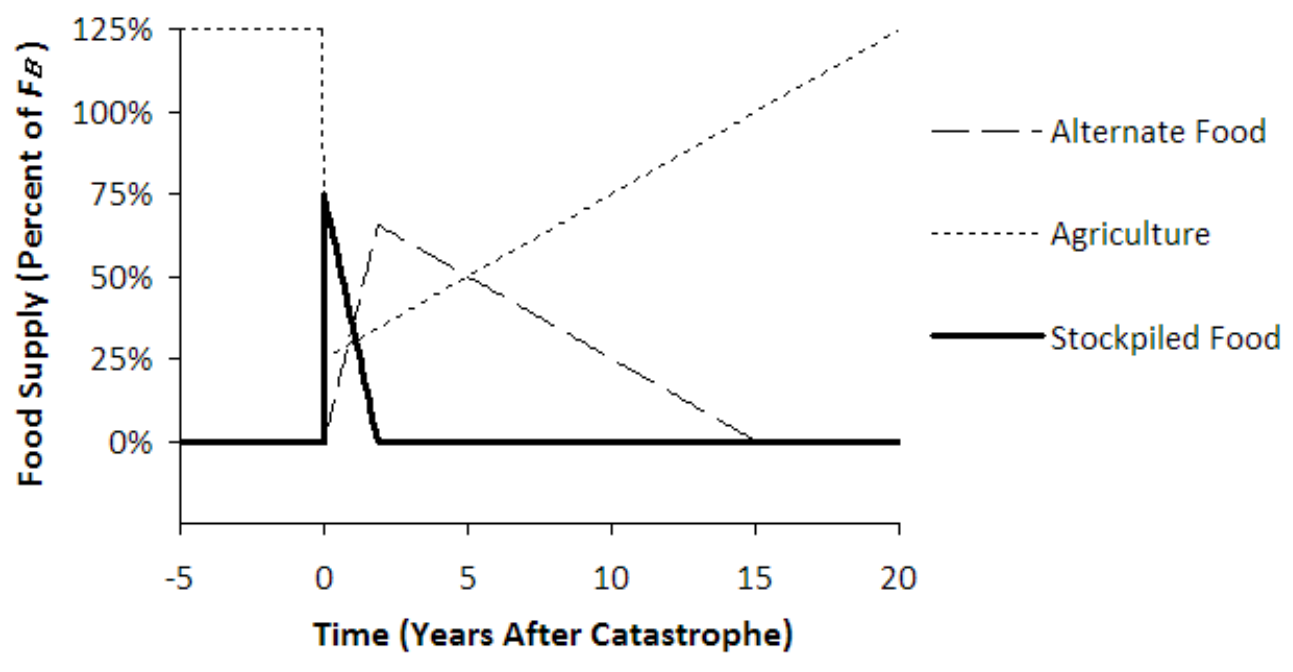

Figure 5. Food supply contributions from agriculture, alternative food, and food stockpile in a hypothetical food catastrophe scenario.

\section{Conclusion}

A variety of risks threaten catastrophic disruption to global food supplies. Indeed, food supply disruption is one of the largest classes of global catastrophic risk. So many known global catastrophic risks threaten food supply disruption that it is likely that some not-yet-known global catastrophic risks would also threaten food supply disruption. Furthermore, some of these catastrophes may not be prevented. For these reasons, resilience to global food supply catastrophe is an important objective.

We have analyzed three major means of increasing resilience to global food supply catastrophe: food stockpiling, agriculture, and alternative foods. Food stockpiles are versatile but expensive. Agriculture is efficient but less viable in certain catastrophe scenarios. Alternative 
Baum, S.D., Denkenberger, D.C., A Pearce, J.M., Robock, A., Winkler, R. Resilience to global food supply catastrophes. Environment, Systems and Decisions 35(2), pp 301-313 (2015). DOI: 10.1007/s10669-015-9549-2

foods are inexpensive but need to be scaled up post-catastrophe and may face issues of social acceptability. Because of this, the optimal portfolio of food options will typically include some of each, and will additionally vary by location as regions vary in population and access to food input resources. Precise quantitative optimization of the optimal portfolio can be assessed from the research program we have outlined.

Furthermore, if the catastrophe shuts down transportation, then resilience requires local selfsufficiency in food. Food supply resilience thus requires not just the food itself, but also the accompanying systems of food production and distribution. For food production, this includes access to stockpiles and resource inputs for agriculture or alternative foods. For food distribution, this includes transportation systems (at least on the local scale) as well as social systems to ensure sufficient access to food for everyone in the community.

Overall, increasing food supply resilience can play an important role in global catastrophic risk reduction. However, it is unwise to attempt maximizing food supply resilience, because doing so comes at the expense of other important objectives, including catastrophe prevention. The exact role of food supply resilience in an overall portfolio of global catastrophic risk reduction, as well as the specific investments in food supply resilience that should be made, are both important topics worthy of ongoing research.

\section{Acknowledgments}

We thank Tony Barrett and three anonymous reviewers for helpful comments on an earlier version of this paper, and Melissa Thomas-Baum for assistance in preparing the graphics. Any remaining errors or other shortcomings are the authors' alone. Alan Robock is supported by U.S. National Science Foundation grants AGS-1157525, GEO-1240507, and AGS-1430051.

\section{References}

Adler MD, Posner EA (2006) New Foundations of Cost-Benefit Analysis. Cambridge, MA: Harvard University Press

Ambrose SH (1998) Late Pleistocene human population bottlenecks, volcanic winter, and differentiation of modern humans. Journal of Human Evolution 34(6):623-651

Aven T (2011) On some recent definitions and analysis frameworks for risk, vulnerability, and resilience. Risk Analysis 31(4):515-522

Barrett AM, Baum SD, Hostetler KR (2013) Analyzing and reducing the risks of inadvertent nuclear war between the United States and Russia. Science and Global Security 21(2):106133

Baum SD, Maher TM Jr, Haqq-Misra J (2013). Double catastrophe: Intermittent stratospheric geoengineering induced by societal collapse. Environment, Systems and Decisions 33(1):168-180

Baum SD, Handoh IC (2014) Integrating the planetary boundaries and global catastrophic risk paradigms. Ecological Economics 107:13-21

Beckstead N (2013) On The Overwhelming Importance Of Shaping The Far Future. Doctoral Dissertation, Department of Philosophy, Rutgers University

Bostrom N (2002) Existential risks: Analyzing human extinction scenarios and related hazards. Journal of Evolution and Technology, 9

Bostrom N, Ćirković M (2008). Global Catastrophic Risks. Oxford: Oxford University Press 
Baum, S.D., Denkenberger, D.C., A Pearce, J.M., Robock, A., Winkler, R. Resilience to global food supply catastrophes. Environment, Systems and Decisions 35(2), pp 301-313 (2015). DOI: 10.1007/s10669-015-9549-2

Butzer KW (2012) Collapse, environment, and society. Proceedings of the National Academy of Sciences 109(10):3632-3639

Cassidy ES, West PC, Gerber JS, Foley JA (2013). Redefining agricultural yields: From tonnes to people nourished per hectare. Environmental Research Letters 8(3): 034015, DOI:10.1088/1748-9326/8/3/034015.

Denkenberger D, Pearce J (2014) Feeding Everyone No Matter What: Managing Food Security After Global Catastrophe. Waltham, MA: Academic Press

Denkenberger DC, Pearce JM (2015). Feeding everyone: Addressing the food crisis in the event of global catastrophe. Futures, forthcoming, doi:10.1016/j.futures.2014.11.008.

Diamond J (2005) Collapse: How societies choose to fail or succeed. London: Penguin

Do T, Anderson K, Brorsen BW (2010) The World's Wheat Supply. Oklahoma Cooperative Extension Service

Dreze J, Sen A, Hussain A (1995) The Political Economy of Hunger: Selected Essays. Oxford: Oxford University Press

Dudley JP, Woodford MH (2002). Bioweapons, biodiversity, and ecocide: Potential effects of biological weapons on biological diversity. Bioscience 52(7): 583-592

Flynn J, Kasperson R, Kunreuther H, Slovic P (1992). Time to rethink nuclear waste storage. Issues in Science and Technology 8(4):42-48

Haimes YY (2009) On the definition of resilience in systems. Risk Analysis 29(4):498-501

Harsanyi JC (1975). Can the maximin principle serve as a basis for morality? A critique of John Rawls’s theory. American Political Science Review 69(2):594-606

Haslam M, Petraglia M (2010) Comment on "Environmental impact of the 73ka Toba supereruption in south Asia” by MAJ Williams, SH Ambrose, S. van der Kaars, C. Ruehlemann, U. Chattopadhyaya, J. Pal and PR Chauhan [Palaeogeography, Palaeoclimatology, Palaeoecology 284 (2009) 295-314]. Palaeogeography, Palaeoclimatology, Palaeoecology 296(1-2):199-203

Hardin G (1974) Lifeboat ethics. Psychology Today, September

Helfand I (2013) Nuclear Famine: Two Billion People at Risk. International Physicians for the Prevention of Nuclear War Physicians for Social Responsibility. http://www.psr.org/assets/pdfs/two-billion-at-risk.pdf

Hellman M (2008) Risk analysis of nuclear deterrence. The Bent of Tau Beta Pi, Spring:14-22 Ho M (2012) Teredo navalis. Animal Diversity Web, University of Michigan. http://animaldiversity.ummz.umich.edu/site/accounts/information/Teredo navalis.html

Jebari K (2014) Existential risks: Exploring a robust risk reduction. Science \& Engineering Ethics, forthcoming, DOI:10.1007/s11948-014-9559-3

Jones JW, Hoogenboom G, Porter CH, Boote KJ, Batchelor WD, Hunt LA, et al. (2003) The DSSAT cropping system model. European Journal of Agronomy 18(3-4):235-265

Kaufman F (2012) How to fight a food crisis. Los Angeles Times, 21 September.

Lane CS, Chorn BT, Johnson TC (2013) Ash from the Toba supereruption in Lake Malawi shows no volcanic winter in East Africa at $75 \mathrm{ka}$. Proceedings of the National Academy of Sciences 110(20):8025-8029

Lenton TM, Held H, Kriegler E, Hall JW, Lucht W, Rahmstorf S, Schellnhuber HJ (2008) Tipping elements in the Earth's climate system. Proceedings of the National Academy of Sciences 105(6):1786-1793 
Baum, S.D., Denkenberger, D.C., A Pearce, J.M., Robock, A., Winkler, R. Resilience to global food supply catastrophes. Environment, Systems and Decisions 35(2), pp 301-313 (2015). DOI: 10.1007/s10669-015-9549-2

Leuthold RH, Triet H, Schildger B (2004) Husbandry and breeding of African giant termites (Macrotermes jeanneli) at Berne Animal Park. Zoologische Garten:72(1), 26-37

Linkov I, Fox-Lent C, Keisler J, Della Sala S, Sieweke J (2014) Risk and resilience lessons from Venice. Environment Systems and Decisions 34:378-382

Lowder SK, Skoet J, Singh S (2014) What do we really know about the number and distribution of farms and family farms worldwide? ESA Working Paper No. 14-02. Food and Agriculture Organization of the United Nations: Agricultural Development Economics Division

Maher TM Jr, Baum SD (2013) Adaptation to and recovery from global catastrophe. Sustainability 5(4):1461-1479

Mann CC (1999). Genetic engineers aim to soup up crop photosynthesis. Science 283(5400):314-316

Mason B, Pyle DM, Oppenheimer C (2004). The size and frequency of the largest explosive eruptions on Earth. Bulletin of Volcanology 66(8):735-748

Matheny JG (2007) Reducing the risk of human extinction. Risk Analysis 27(5):1335-1344

Matthews HD, Caldeira K (2007) Transient climate-carbon simulations of planetary geoengineering. Proceedings of the National Academy of Sciences 104(24):9949-9954

Mills MJ, Toon OB, Lee-Taylor J, Robock A (2014) Multi-decadal global cooling and unprecedented ozone loss following a regional nuclear conflict. Earth’s Future, 2(4):161-176.

NAS (National Academy of Sciences) (2012) Disaster resilience: a national imperative. Washington DC, United States. http://www.nap.edu/catalog.php?record id=13457

Ng Y-K (1991) Should we be very cautious or extremely cautious on measures that may involve our destruction? Social Choice and Welfare 8:79-88

Otway HJ, Von Winterfeldt D (1982). Beyond acceptable risk: On the social acceptability of technologies. Policy Sciences 14(3):247-256

Özdoğan M, Robock A, Kucharik CJ (2013) Impacts of a nuclear war in South Asia on soybean and maize production in the Midwest United States. Climatic Change 116(2):373-387.

Park J, Seager TP, Rao PSC, Convertino M, Linkov I (2013) Integrating risk and resilience approaches to catastrophe management in engineering systems. Risk Analysis 33(3):356-367

Parrett CM (2012) LDS Preparedness Manual, Version 8.0 (1 June), Book 2: Temporal Preparedness, General Membership Edition

Petraglia M, Korisettar R, Boivin N, Clarkson C, Ditchfield P, Jones S, et al. (2007) Middle Paleolithic assemblages from the Indian subcontinent before and after the Toba supereruption. Science 317(5834):114-116

Posner R (2004) Catastrophe: Risk and Response. Oxford: Oxford University Press

Rampino MR (2002) Supereruptions as a threat to civilizations on Earth-like planets. Icarus 156(2):562-569

Robock A, Oman L, Stenchikov GL (2007a) Nuclear winter revisited with a modern climate model and current nuclear arsenals: Still catastrophic consequences. Journal of Geophysical Research: Atmospheres 112(D13), doi: 10.1029/2006JD008235

Robock A, Oman L, Stenchikov GL, Toon OB, Bardeen C, Turco RP (2007b) Climatic consequences of regional nuclear conflicts. Atmospheric Chemistry and Physics 7(8):20032012 
Baum, S.D., Denkenberger, D.C., A Pearce, J.M., Robock, A., Winkler, R. Resilience to global food supply catastrophes. Environment, Systems and Decisions 35(2), pp 301-313 (2015). DOI: 10.1007/s10669-015-9549-2

Robock A, Ammann CM, Oman L, Shindell D, Levis S, Stenchikov G (2009) Did the Toba volcanic eruption of $~ 74$ ka BP produce widespread glaciation? Journal of Geophysical Research: Atmospheres, 114(D10), doi: 10.1029/2008jd011652

Robock A (2014). Reply to comment on "The latest on volcanic eruptions and climate”. Eos, Transactions American Geophysical Union, 95(39):353, doi: 10.1002/2014eo390009

Rockström J, Steffen W, Noone K, Persson Å, Chapin FS III, Lambin E, et al. (2009a) Planetary boundaries: Exploring the safe operating space for humanity. Ecology and Society 14(2):32, http://www.ecologyandsociety.org/vol14/iss2/art32

Rockström J, Steffen W, Noone K, Persson Å, Chapin FS III, Lambin E, et al. (2009b) A safe operating space for humanity. Nature 461:472-475

Sagan C (1983) Nuclear war and climatic catastrophe: Some policy implications. Foreign Affairs 62:257-292

Saigo H (2000) Agricultural biotechnology and the negotiation of the biosafety protocol. Georgetown International Environmental Law Review 12(3):779-816

Schneider S (1976) The Genesis Strategy: Climate and Global Survival. New York: Springer

Sparks S, Pyle D, Oppenheimer C, Rymer H, Grattan J (2005) Super-Eruptions: Global Effects and Future Threats. London: Geological Society of London

Timmreck C, Graf HF, Lorenz SJ, Niemeier U, Zanchettin D, Matei D, et al. (2010) Aerosol size confines climate response to volcanic super-eruptions. Geophysical Research Letters, 37(24), doi: 10.1029/2010gl045464

Toon OB, Robock A, Turco RP (2008) Environmental consequences of nuclear war. Physics Today 61(12):37-42

Unibio (2014) What Is Uniprotein ${ }^{\circledR}$ ? http://www.unibio.dk/?page id=47

Valdes P (2011) Built for stability. Nature Geoscience 4(7):414-416

World Food Programme (2014) Hunger Statistics. http://www.wfp.org/hunger/stats

Xia L, Robock A (2013) Impacts of a nuclear war in south Asia on rice production in mainland China. Climatic Change 116(2):357-372

Xia L, Robock A, Cole J, Curry CL, Ji D, Jones A, et al. (2014) Solar radiation management impacts on agriculture in China: A case study in the geoengineering model intercomparison project (GeoMIP). Journal of Geophysical Research: Atmospheres 119(14):8695-8711

Xia L, Robock A, Mills M, Stenke A, Helfand I (2015) Global famine after a regional nuclear war. Earth’s Future, in press. http://climate.envsci.rutgers.edu/pdf/NWXIA4.pdf 